\title{
Are the Members of Your Team Linchpins?
}

Pauline Blachford

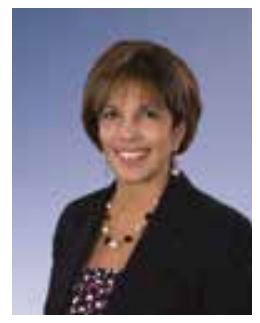

Pauline consults optometrists on recalling and other elements of practice management. She has worked on the business side of optometry for over two decades, and is highly sought after for her results-based strategies. Through her private consultations, conference presentations and regular columns in the Canadian Journal of Optometry, Pauline reaches optometrists and their teams across North America with her thought-provoking, engaging and inspiring insights. For more information, visit paulineblachford.com.

$\mathrm{C}$ onsider the following: according to a 2013 employee engagement report conducted by Gallup, less than one in three employees feel engaged at work, meaning the vast majority of workers - in this case, 70 per cent of American workers - are not reaching their full potential. ${ }^{1}$ Nearly one in five employees were so disengaged that they were more likely to negatively influence coworkers, miss workdays and drive customers away. ${ }^{2}$

Now, consider this: research conducted by Brand Identity, Inc. found that nearly $80 \%$ of leaders don't feel that their staff consistently demonstrates drive, energy or a focus on results. Brand Identity's research also discovered that $70 \%$ of leaders do not believe that their employees are as committed as they should be to increasing sales, or supporting the growth of the business they work for. ${ }^{3}$

These two pieces of research highlight a critical disconnect. In June, I had the opportunity to speak directly to a room full of optometric assistants at the Saskatchewan Association of Optometry conference in Regina about seeing the bigger picture in terms of the role they could play in their current positions. Identifying areas for improvement, proposing new ideas and executing them - all for the benefit of your practice - is what I refer to as being a linchpin, a term popularized in this context by author Seth Godin. ${ }^{4}$

A linchpin employee has drive, energy and focus: qualities that leaders in Brand Identity's research found to be missing in most of their staff members. I've written before about the benefits that come from engaging your employees, ${ }^{5}$ but simply put: when companies engage their customers and their staff, they see a $240 \%$ boost in performance-related business outcomes, compared with companies who write engagement off. ${ }^{6}$ The data is there, but do employees want to be linchpins?

At the conference in Regina, I asked optometry employees directly whether they knew why they were in their current roles at their respective optometry practices. ${ }^{7}$ Around $43 \%$ of the respondents answered that they discover their why - and the satisfaction that comes with it - from knowing where they add the greatest value.

Additionally, when asked what they would like to get out of their role, $29 \%$ of participants wanted more stimulation and personal satisfaction, and $18 \%$ more training opportunities. Coupled with the desire to add value, that is a lot of untapped potential, especially when increased employee engagement translates into increased productivity and bottom-line results.

What inspires and engages your employees should not be overlooked: this is a key insight into what type of rewards or opportunities might drive your staff to work with you to build your practice. After all, who wouldn't want a recaller to make it their personal mission to ensure each OD's schedule is fully booked every week? Or a receptionist who boosts eyewear sales by ensuring patients' eye care needs are met upon checkout?

Your employees likely have the desire to be more challenged or engaged at work, as well as the ideas for how they can better your business. During my presentation, the ideas that optometry staff shared with me included having ODs in regular staff meetings, brightening office colours, completing and mailing the rebate forms for patients who purchase a year's supply of contact lenses, and direct billing to insurance companies. These were all valuable suggestions, and the staff in my session were engaged and brimming with ideas to share - they just needed to feel incentivized, empowered and trusted to contribute them.

There are several ways leaders can begin creating a practice environment where staff have the opportunities to be employee superstars. According to Vistage speaker Gregg Lederman, managing partner at Brand Integrity, Inc., employers need to set expectations with their employees, communicate those expectations well and hold staff accountable. ${ }^{8}$ Offering training, engaging individual strengths, advancing staff members and motivating them are also great ways to create a linchpin team of staff in your practice. ${ }^{9}$

On the employee side, I coach optometry staff that being a linchpin in any role is achievable by following five key steps: identify the needs, strengths and opportunities of 
their practice; understand their own capacity to contribute; implement ideas that play to their personal skills and the needs of their practice; foresee the obstacles that may challenge their ideas; and measure the results of their execution to ensure their ideas are having a positive and quantifiable impact. An employee's ability to contribute, however, is always limited by the opportunities they are given to do so. To this end, I also encourage ODs to champion staff brainstorming sessions, and to begin building a practice culture that fosters, supports and rewards the sharing of ideas. When the culture of a practice encourages staff to be linchpins, any employee's ability to come up with their own ideas, voice them, measure them and take ownership of them flourishes, and often leads to success when the five steps above are followed.

At the end of the day, the real bottom line is that your employees are your greatest resource for boosting yours. When optometric assistants own their positions through training and growth, their clinics become a place patients want to visit, where co-workers want to work together and where ODs will be more financially successful.

\section{Footnotes}

1. Gallup. State of the American workplace: employee engagement insights for U.S. business leaders; 2013

2. Ibid at 12 .

3. Vistage International. Creating an extraordinary culture and superstar employees: four steps to avoid the trap of apathy and get maximum productivity and engagement from your staff. 2010

4. For more information on Seth Godin's book, Linchpin: Are You Indispensable? at: www.sethgodin.com.

5. To read more about the bottom-line benefits of engaging your employees, read my past article in the Canadian Journal of Optometry on "Reducing Employee Turnover" at: http://digital.turn-page.com/i/431237-cjo-76-2.

6. Supra note 1 at 55 .

7. Warrell M. Do you know your "why?" 4 questions to find your purpose. Forbes; 2013. Available at: http://www.forbes.com/sites/ margiewarrell/2013/10/30/know-your-why-4-questions-to-tap-the-power-ofpurpose/\#349c1cd0564e.

8. Supra note 3 at 4 .

9. Ingino D. 4-step checklist for creating a linchpin team. StrengthLeader; 2015. Available at: http://www.strengthleader.com/4-step-checklist-for-a-creatinga-linchpin-team.

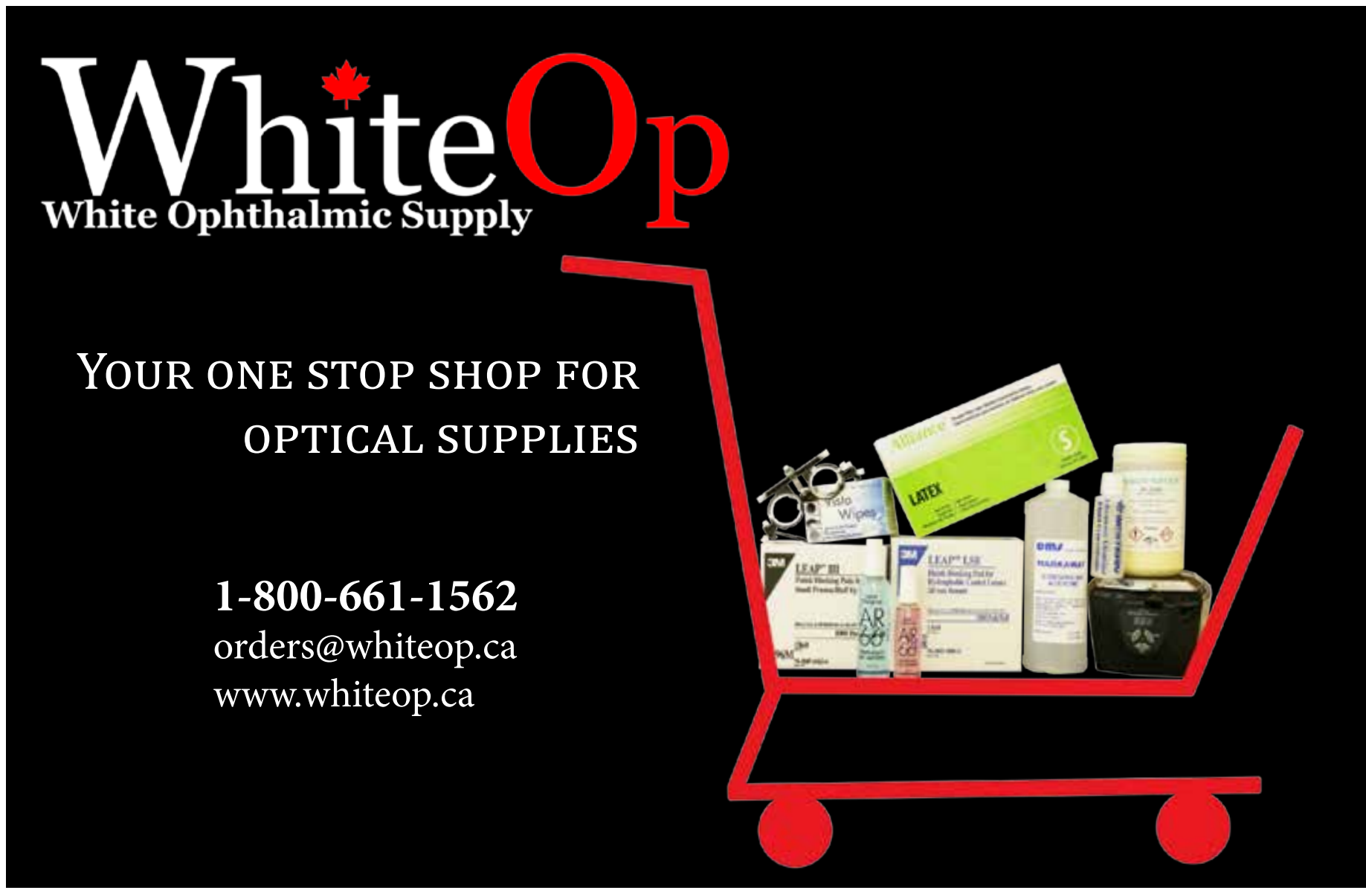

